\title{
First Degree Family History of Primary Brain Tumor Negative
}

National Cancer Institute

\section{Source}

National Cancer Institute. First Degree Family History of Primary Brain Tumor Negative. NCI Thesaurus. Code C160169.

The parents, siblings or children of an individual have no history of primary brain tumors. 